Article

\title{
Characteristics of Transient Eddy Fluxes during Blocking Highs Associated with Two Cold Events in China
}

\author{
Yan $\mathrm{Li}^{1,2, *}$, Jinyu Zhang ${ }^{1}$, Yao Lu ${ }^{1}$, Jianlei Zhu ${ }^{3}$ and Juan Feng ${ }^{4}$ \\ 1 College of Atmospheric Sciences, Lanzhou University, Lanzhou 730000, China; \\ zhangjy2017@lzu.edu.cn (J.Z.); luy15@lzu.edu.cn (Y.L.) \\ 2 Key Laboratory of Semi-Arid Climate Change, Ministry of Education, Lanzhou University, \\ Lanzhou 730000, China \\ 3 China-ASEAN Environmental Cooperation Center, Beijing 100035, China; zhu.jianlei@chinaaseanenv.org \\ 4 College of Global Change and Earth System Science (GCESS), Beijing Normal University, \\ Beijing 100875, China; fengjuan@bnu.edu.cn \\ * Correspondence: liyanlz@lzu.edu.cn
}

Received: 28 March 2019; Accepted: 24 April 2019; Published: 1 May 2019

\begin{abstract}
In Eastern Asia, two categories of cold air outbreaks, ordinary type and extensive and persistent type, usually occur during boreal winter, with obviously different circulation backgrounds. Blocking highs, which play an important role in cold events, are closely related to the evolution of transient eddies in their dynamical mechanism. This paper investigates the characteristics of thermal-dynamical transport of transient eddies associated with blocking events in two cold air events: a low-temperature, snowfall, and freezing event in early 2008 and a cold wave in January 2016. The results suggest that there is a convergence of transient eddy momentum and heat transport around blocking high locations during both cold events, which are beneficial for establishing and maintaining the blocking events. Moreover, the convergence of transient eddy momentum and heat transport is stronger in the 2016 event than in the 2008 event, with a northward shift of the convergence centers. Further analysis shows that the blocking high location is controlled by the convergence of Eliassen-Palm (E-P) flux in both events, which contributes to the westerly wind deceleration and provides a beneficial background for the development of blocking events. Moreover, the anticyclonic Rossby wave breaking (RWB) event occurs two days prior to the onset of blocking and weakens along with the collapse of blocking in both cold events; however, the RWB has a longer duration, stronger intensity, and more north-eastward location in the 2016 event than for the 2008 event. These results indicate that the effect of a synoptic-scale eddy is one important factor influencing different characteristics of the blocking highs and is related to different weather phenomena during the two cold events.
\end{abstract}

Keywords: blocking highs; cold events; transport of momentum and heat; E-P flux; Rossby wave breaking

\section{Introduction}

During the boreal winter, East Asia is frequently subjected to the impacts of cold events. The cold events are featured by a steep rise in surface pressure, a strengthening of northerly surface winds, and a sharp drop in surface temperature [1]. These cold events exert tremendous environmental, societal, and economic influences over East Asia [2]. Additionally, the Intergovernmental Panel on Climate Change Fourth Assessment Report (IPCC AR4) indicates that record-breaking extreme weather events, such as low-temperature events and cold waves, will frequently occur in the future [3]. These extreme 
cold events usually cause once-in-a-decade disasters compared with general cold events [4]. Thus, it is urgent to improve the understanding of physical causes of these cold events.

Previous studies have determined that blocking highs are one of the most important factors for cold events. If blocking circulations are sufficiently strong and persistent, they can divert weather systems from the normal path and result in significant climate anomalies, including extreme climatic events [5]. In Eastern Asia, cold events during the boreal winter occur in relation to the Siberian high $(\mathrm{SH})$ which is the highest sea-level-pressure center in the Northern Hemisphere (NH), in addition to blocking highs, which can be identified in the middle troposphere through a split-flow regime $[1,6,7]$. The onset of an East Asian cold air outbreak by the southward spread of the SH is preceded by the establishment of north-westerly flow via an upper-level ridge lying in front of a high-pressure ridge when the blocking high collapses [8]. As a result, predicting the collapse of the blocking high is the key for skillfully forecasting cold events in Eastern Asia [7]. In view of the close connection between blocking highs and cold events, a study on the dynamical mechanism of blocking highs is essential for the deep understanding of mechanisms and forecasting for cold events.

Many studies have focused on the dynamical mechanisms of blocking highs. First, Yeh [9] discussed the blockings from the perspective of energy dispersion. Then, Rossby [10] considered that blocking highs were partly similar to hydraulic jumps in hydrodynamics but did not provide explanations for the duration of blocking events. Since the 1970s, the dynamical theories of blocking highs have been greatly developed because of the efforts of many scientists by using nonlinear dynamics [11,12]. In terms of dynamical mechanisms for blockings in Eurasian regions, it is widely accepted that the influence of wave train propagation is important during a lifetime of blocking highs. For example, Li [13] declared that the North Atlantic Oscillation (NAO) pattern was closely related to the Urals blocking (UB) event activity via the North Atlantic sea surface temperature (SST) anomaly. Luo et al. [14] suggested that the energy source of the UB establishment mainly came from the North Atlantic basin via energy dispersion or wave train propagation as a negative phase East Atlantic/West Russia (EA/WR) pattern of quasi-stationary waves generated in the North Atlantic region. In addition, the influence of interactions between waves and mean flow, the interactions between waves with different scales, and the topography are also important for the evolution of blocking highs in Eurasia [15].

Transient eddies transport heat and momentum from the subtropics to higher latitudes in the mid-latitudes, which plays an important role in the maintenance of atmospheric circulation as well as blocking highs [16]. A consistent picture has emerged from the copious research on blocking highs that the synoptic-scale wave is important in the life-cycles of blocking events $[6,17]$. For example, Chen [18] examined the dynamic processes during the establishment of blocking flow by a series of daily isentropic potential vorticity charts and found that the transient eddies were crucial in establishing the blocking flows. Athar and Lupo [19] addressed the question of the role of planetary-scale versus synoptic-scale processes during the various stages of the blocking life-cycles and suggested that blocking events from December to May were more synoptic-scale dominant. $\mathrm{Xu}$ and Jin [20] diagnosed the influence of transient eddy fluxes on abnormal blockings and found that anti-cyclonic flow was strengthened by the forcing impacts of transient eddies on mean flow. Yun et al. [21] found that the Tibetan Plateau uplift tended to shift the location of blocking frequencies northward due to notable poleward displacement of the jet stream and transient eddy activities. Therefore, as an important index in the internal atmosphere dynamic process, transient eddies impact the occurrence and sustenance of blocking events and play an important role in the formation of cold events via their anomalous activity.

In Eastern Asia, there are two typical types of cold events, which can be recognized according to their spatial extent and duration: the ordinary cold wave events and the extensive and persistent extreme cold events [22]. To investigate the transport of transient eddies during blocking events and retain the characteristics of transient eddies, we chose two cold events with extraordinary effect but different synoptic characteristics in China in recent winters as representative. One occurred in early 2008 (2008 event); more than 20 provinces and municipalities in southern China experienced 
sustained low temperature, snow, and freezing weather events for more than 20 consecutive days during this cold event [23]. The other occurred in January 2016 (2016 event); during this event, the temperatures in some southern provinces of mainland China were more than $10^{\circ} \mathrm{C}$ lower than the average historical level [24]. Blocking high during the 2016 event is shorter in duration but stronger in intensity compared with that during the 2008 event. Previous work has reported the associated processes of the two cold events. However, a comparison between the two cold events has not been considered, especially from the perspective of transient eddies to reveal different characteristics of these two events. In this paper, we attempted to address the following two questions: (1) What are the different characteristics of transient eddy flux during blocking highs related the two cold events? (2) What is the role of synoptic-scale eddies in impacting the different features of blocking highs and different weather phenomena during these two events?

The remainder of the paper is organized as follows: Section 2 describes the data and methodologies. Sections 3 and 4 analyze the characteristics of momentum and heat transport of transient eddies during the two blocking highs, respectively. Section 5 shows the related information from perspective of Eliassen-Plam flux (E-P flux) and Rossby wave breaking (RWB). The conclusions and discussion are presented in Section 6.

\section{Data and Methodologies}

\subsection{Data}

Geopotential height $(\mathrm{GPH})$, temperature $(\mathrm{T})$, and wind $(\mathrm{u}, \mathrm{v})$ were obtained from the National Centers for Environmental Prediction and National Centers for Atmospheric Research (NCEP/NCAR) ReanalysisI [25]. The dataset is comprised of grid data formed by the reanalysis of global meteorological data from 1948 to the present using observational prediction models and assimilation systems. These data were on a grid with a horizontal resolution of $2.5^{\circ} \times 2.5^{\circ}$ and 17 vertical pressure levels (1000, $925,850,700,600,500,400,300,250,200,150,100,70,50,30,20$, and $10 \mathrm{hPa})$. We used the daily mean dataset from 1979-2016.

\subsection{Methodologies}

\subsubsection{Recognition of a Blocking Event}

In this paper, we employed the blocking index defined by Tibaldi and Molteni [26] (referred to as the T\&M index). The southern $500 \mathrm{hPa}$ geopotential height gradient (GHGS) and the northern $500 \mathrm{hPa}$ geopotential height gradient (GHGN) were computed as follows:

$$
\begin{aligned}
G H G S & =\frac{Z\left(\phi_{0}\right)-Z\left(\phi_{s}\right)}{\phi_{0}-\phi_{s}} \\
G H G N & =\frac{Z\left(\phi_{n}\right)-Z\left(\phi_{0}\right)}{\phi_{n}-\phi_{0}}
\end{aligned}
$$

where $\phi_{n}=80^{\circ} \mathrm{N}+\delta, \phi_{0}=60^{\circ} \mathrm{N}+\delta, \phi_{s}=40^{\circ} \mathrm{N}+\delta$, and $\delta=-5^{\circ}, 0^{\circ}, 5^{\circ}$.

An instantaneous blocking (IB) value was assigned to a grid point if both of the following conditions were satisfied:

(1) GHGS $>0$,

(2) GHGN $<-10 \mathrm{~m} \cdot$ degree $^{-1}$.

The blocking index is then given by the value of GHGS. Basically, the T\&M method is a digital analysis tool for a classical climatology of blocking events [27], which is simple and easy to compute. In addition, this method objectively focuses on high-latitude blocking highs which are closely related to winter cold events in China [22]. Finally, the T\&M method is local and instantaneous, ideally suited 
for real-time atmospheric monitoring, isolating regions of easterly flow at $500 \mathrm{hPa}$ in longitude-time graphs (Hovmöller diagrams) and is displayed visually by many operational departments [28].

\subsubsection{Momentum and Heat Transport of Transient Eddies}

In this study, we used a decomposition method for the atmospheric variables. According to the principle of physical decomposition [29], the temporal anomalous fields, such as $u^{\prime}, v^{\prime}$ and $T^{\prime}$, are defined on a calendar date $(t)$ in the year $(y)$ at latitude $(\varphi)$. The specific method is as follows:

An observational daily mean variable field $F(\lambda, \varphi, t)_{y}$, such as $G P H, u, v$ or $T$, is defined on a calendar date $(t)$ in a year $(y)$ at a spatial grid point of longitude $(\lambda)$ and latitude $(\varphi)$. Then, it can be decomposed into a climatic field $\hat{F}(\lambda, \varphi, t)$ and temporal anomaly field $F^{\prime}(\lambda, \varphi, t)_{y}$ :

$$
F(\lambda, \varphi, t)_{y}=\hat{F}(\lambda, \varphi, t)+F^{\prime}(\lambda, \varphi, t)_{y}
$$

The climatic field was estimated by averaging 30 years (1979-2008) of data based on the NCEP/NCAR reanalysis data on the calendar date $(t)$. Moreover, we used 10-day running mean field $\bar{F}(\lambda, \varphi, t)_{y}$ of daily climatology to ensure strong representation of the climatology:

$$
\hat{F}(\lambda, \varphi, t) \sum_{1979}^{2008} \bar{F}(\lambda, \varphi, t)_{y} / 30
$$

The temporal anomalous fields can be derived after removing the climatic fields from the original observations. One is the zonal-averaged anomalous fields on calendar date $(t)$ in year $(y)$ at latitude $(\varphi)$ :

$$
[F(\lambda, \varphi, t)]_{y}^{z^{\prime}}=\sum_{\lambda=\lambda_{1}}^{\lambda_{2}}\left[F(\lambda, \varphi, t)_{y}-\hat{F}(\lambda, \varphi, t)\right] /\left(\lambda_{2}-\lambda_{1}+1\right)
$$

This component is referred to as the zonal-averaged (or planetary-scale) anomaly that was used in this paper. The zonal-mean momentum and heat transport of transient eddies are represented by $\left[u^{\prime} v^{\prime}\right]$ and $\left[v^{\prime} T^{\prime}\right]$, respectively. The square brackets ([ ]) indicate the zonal mean [29].

\subsubsection{The Generalized E-P Flux}

In order to supplement our study, we used the generalized Eliassen-Palm relation defined by Andrews and Mcintyre [30]. According to the transformed Eulerian mean formulation under the approximation of $\beta$ plane, the expression of the E-P flux is defined as follows:

$$
F \equiv j F_{y}+k F_{z}
$$

The E-P flux is a vector in the meridional $(y, z)$ plane, which for large-scale quasi-geostrophic eddies has the components:

$$
\begin{gathered}
F_{y}=-\rho_{0} \overline{u^{\prime} v^{\prime}} \\
F_{z}=\rho_{0} f_{0} R \overline{v^{\prime} T^{\prime}} /\left(N^{2} H\right)
\end{gathered}
$$

where $\rho_{0}$ indicates air density, $u^{\prime}, v^{\prime}, T^{\prime}$ are the disturbance of $u, v$ and $T, f_{0}$ is the Coriolis parameter, and $\mathrm{R}$ shows the gas constant for dry air. $N$ and $H$ represent buoyancy frequency and scale height, respectively.

Then, the divergence of E-P flux is written as:

$$
\nabla \cdot F=\frac{\partial F_{y}}{\partial y}+\frac{\partial F_{z}}{\partial z}
$$




\subsubsection{The Ertel's Potential Vorticity (PV)}

The quantitative PV framework we used in this paper was developed by Teubler and Riemer [31] based on the concept of baroclinically coupled Rossby waves and their downstream development. The hydrostatic form of Ertel's PV on an isentropic surface is written as:

$$
P V=\sigma^{-1}(\zeta+f)
$$

where $\zeta$ represents the vertical component of relative vorticity on an isentropic surface, $f$ is the Coriolis parameter.

$$
\sigma^{-1}=g \frac{\partial \theta}{\partial p}
$$

where $g, p$ and $\theta$ represent the gravity acceleration, pressure, and potential temperature.

In this study, PV was analyzed on isentropic surface coinciding with tropopause in middle-high latitudes [32]. As the study period was in winter, the isentropic surface was selected as $\theta=315 \mathrm{~K}$, on which reversal of PV in the meridional gradient can reflect information of RWB.

\subsubsection{Two Cases of Cold Events}

Generally, climatic research should hold statistical significance; however, it is easy to filter information from the aspect of transient eddies because of their synoptic scale. As a result, two cold events, one occurring from January 10 to February 2, 2008, and the other from January 21-25, 2016, were chosen in this study as representative. During the two events, synoptic characteristics were very different. In early 2008, the weather was characterized as having long-duration low temperatures, snow fall, and freezing. In addition, in January 2016, most parts of China suffered from the strong cold surge, which featured a sharp drop in temperature (i.e., above $12^{\circ} \mathrm{C}$ ). This cold surge helped many places of China build a new record for cold temperatures during January in climatology.

Previous studies have verified the close relationship between blocking highs and the occurrences of these two cold events. For example, Nath and Chen [15] concluded that the extraordinary persistence of the cold event in 2008 had been linked with an anomalous blocking high over the Urals-Siberia regions. Nie et al. [33] considered that the development and decay of mid-latitude atmospheric blocking high contributed to the sudden drop of air temperatures in January 2016. It is indicated that features of blocking highs during these two events are different.

Figure 1 shows the T\&M index in Eurasian middle-high latitudes during the two events. From Figure $1 \mathrm{a}$ and combining the daily synoptic maps, it is found that there were mainly four blocking high processes during the low-temperature, snowy, and freezing rain event in 2008, from January 10 to 15,18 to 22, 25 to 29, and January 31 to February 2 (Figure 1a), which is consistent with the previous study [34]. Here, only the second process (18 to 22 January) was considered for its severe climatic impacts and long duration in this study. The range of longitude was chosen in the Urals region $\left(55^{\circ}-85^{\circ} \mathrm{E}\right)$ from Figure 1a. In the other cold event in January 2016, the blocking high in the Baikal regions $\left(90^{\circ}-120^{\circ} \mathrm{E}\right)$ was very strong, established on January 21 and broke down on January 23 (Figure 1b). It is seen that the intensity of the blocking high in the 2016 event is stronger than that in the 2008 event. Based on the results in Figure 1 and previous studies [15,33,34], the blocking high in the 2008 event is longer on duration, weaker in intensity, more southward in latitudes, and more westward in longitudes compared with the blocking high in the 2016 event. 
(a)

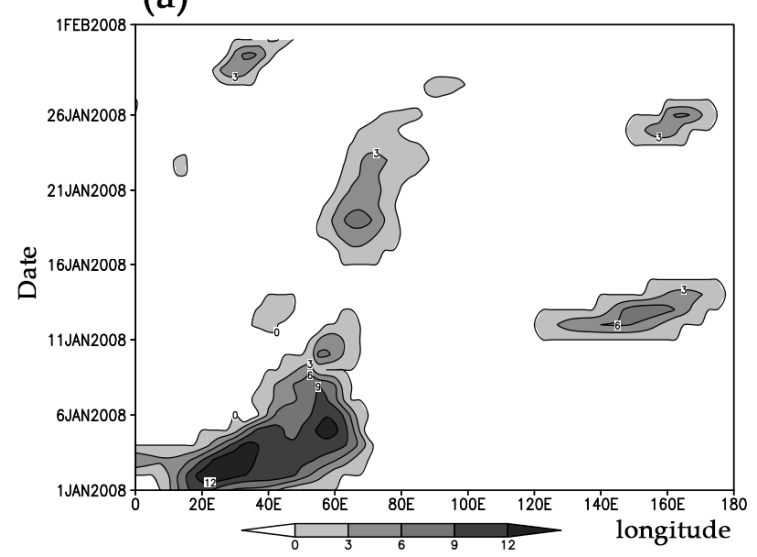

(b)

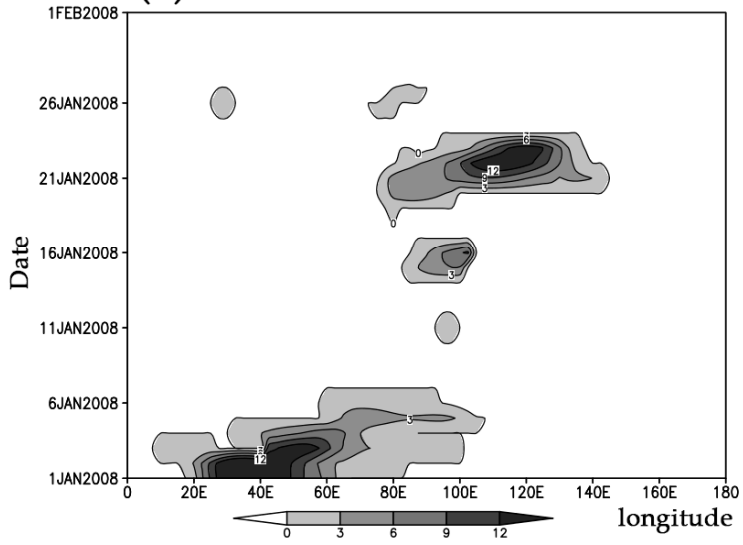

Figure 1. Tibaldi and Molteni (T\&M) blocking index in Eurasian middle and high latitudes during the two events. Unit: $m \cdot$ degree $^{-1}$. (a) from January 1 to February 1 2008, (b) from January 1 to February 12016.

We investigated the daily variation characteristics of thermal-dynamical transport of transient eddies in blocking high evolution from two days prior (Day -2$)$ to three days after $($ Day +3$)$ the establishment of the blocking high. The reason we chose this period is that the characteristics of the transient eddies were the most remarkable during the entire lifetime of the blocking high.

\section{Characteristics of Transient Eddy Momentum Transport}

The evolution of blocking highs is accompanied by momentum transport, and the contribution of momentum should be different as blocking highs develop. This section attempts to analyze the characteristics of momentum transport by transient eddies during the two blocking highs.

Figures 2 and 3 illustrate the vertical distribution of momentum transport of transient eddies $\left(\left[u^{\prime} v^{\prime}\right]\right)$ and the zonal wind $([u])$ during the blocking highs in the 2008 and 2016 events, respectively. A positive (negative) $\left[u^{\prime} v^{\prime}\right]$ suggests that the momentum is transported northward (southward). A positive (negative) zonal wind shows that it is westerly (easterly).

During the 2008 event, there were two positive centers of $\left[u^{\prime} v^{\prime}\right]$ located at approximately $35^{\circ} \mathrm{N}$ and $55^{\circ} \mathrm{N}$ at $300 \mathrm{hPa}$ on Day -2 , respectively. Furthermore, there was a maximum center of $[u]$ with a wind speed up to $50 \mathrm{~m} \cdot \mathrm{s}^{-1}$ at approximately $30^{\circ} \mathrm{N}$ at $200 \mathrm{hPa}$, which is related to the subtropical jet (STJ). Although the maintenance of STJ is not decided by the transient eddy transport, but by the mean meridional circulation, i.e., the Hadley circulation, the $\left[u^{\prime} v^{\prime}\right]$ near $35^{\circ} \mathrm{N}$ transported northward may be associated with the STJ [35]. The weak easterlies existed at mid-latitudes and may be influenced by the previous blocking events. One day later, the transient eddy momentum transported northward weakened at $35^{\circ} \mathrm{N}$ but strengthened at approximately $55^{\circ} \mathrm{N}$. The weak negative $\left[u^{\prime} v^{\prime}\right]$ appeared at $60^{\circ}-70^{\circ} \mathrm{N}$. There was thus a convergence of $\left[u^{\prime} v^{\prime}\right]$ at approximately $60^{\circ} \mathrm{N}$, where the blocking high was located. The convergence of $\left[u^{\prime} v^{\prime}\right]$ supported momentum for blocking event development. The transient eddy transport decelerated the westerly and helped to maintain the blocking high, which is consistent with the studies of Trenberth, K. E [36]. On Day 0, the vertical distribution of $\left[u^{\prime} v^{\prime}\right]$ was quite different from that on Day -2 or Day -1 . The region distributed by positive $\left[u^{\prime} v^{\prime}\right]$ at approximately $35^{\circ} \mathrm{N}$ on Day -1 had been occupied by negative $\left[u^{\prime} v^{\prime}\right]$, and southward transient eddy momentum transport was present at approximately $30^{\circ} \mathrm{N}$. The maximum $\left[u^{\prime} v^{\prime}\right]$ transported northward up to $160 \mathrm{~m}^{2} \cdot \mathrm{s}^{-2}$ lay at $55^{\circ} \mathrm{N}, 250 \mathrm{hPa}$. Another positive $\left[u^{\prime} v^{\prime}\right]$ was located at $70^{\circ}-80^{\circ} \mathrm{N}$ with the center up to $120 \mathrm{~m}^{2} \cdot \mathrm{s}^{-2}$ at $75^{\circ} \mathrm{N}, 300 \mathrm{hPa}$. The convergence of $\left[u^{\prime} v^{\prime}\right]$ still existed near $60^{\circ} \mathrm{N}$. The easterly at $40^{\circ}-60^{\circ} \mathrm{N}$ and the westerly at $60^{\circ}-80^{\circ} \mathrm{N}$ were larger than those on Day -1 , which illustrates a stronger blocking event. In addition, the STJ continued strengthening and was up to $60 \mathrm{~m} \cdot \mathrm{s}^{-1}$ at $30^{\circ} \mathrm{N}, 250 \mathrm{hPa}$. The results verified that the jet is closely associated with transient eddy activities, which indicates the important role of the jet in influencing transient eddy activities [35]. On Day +1 , the negative $\left[u^{\prime} v^{\prime}\right]$ at 
approximately $30^{\circ} \mathrm{N}$ strengthened, but the positive $\left[u^{\prime} v^{\prime}\right]$ located between $50^{\circ} \mathrm{N}$ and $70^{\circ} \mathrm{N}$ considerably weakened. The convergence of $\left[u^{\prime} v^{\prime}\right]$ also weakened, and the center of convergence moved southward by approximately 5 degrees of latitude. One day later, the negative $\left[u^{\prime} v^{\prime}\right]$ around $30^{\circ} \mathrm{N}$ continues to strengthen. Its intensity and range of positive $\left[u^{\prime} v^{\prime}\right]$ at $40^{\circ}-60^{\circ} \mathrm{N}$ were weaker than those on Day +1 . The negative $\left[u^{\prime} v^{\prime}\right]$ appeared at $70^{\circ} \mathrm{N}$, at which there was positive $\left[u^{\prime} v^{\prime}\right]$ on Day +1 . The convergence of [ $\left.u^{\prime} v^{\prime}\right]$ always existed at $60^{\circ} \mathrm{N}$ and changed little. On Day +3 , the area south of $30^{\circ} \mathrm{N}$ was dominated by negative $\left[u^{\prime} v^{\prime}\right]$ and was much larger than that on Day +2 . At the same time, a momentum transport convergence of transient eddies still existed where the blocking high occurred, but was relatively weak. The blocking high collapsed in this process. In addition, January 21 represented four days before the establishment of the blocking high in the next process. The convergence of momentum transport saves energy for the establishment of the next blocking high.

During the 2016 event, the $\left[u^{\prime} v^{\prime}\right]$ transported northward was located at $20^{\circ}-80^{\circ} \mathrm{N}$, the two centers of which lay at $35^{\circ} \mathrm{N}$ and $55^{\circ} \mathrm{N}$ on Day -2 . The STJ with $70 \mathrm{~m} \cdot \mathrm{s}^{-1}$ is at $30^{\circ} \mathrm{N}, 200 \mathrm{hPa}$. On Day -1 , the two pieces of $\left[u^{\prime} v^{\prime}\right]$ transported northward strengthen and move southward. Therefore, the easterly at mid-latitudes also moved southward. There was a convergence of $\left[u^{\prime} v^{\prime}\right]$ located at approximately $65^{\circ} \mathrm{N}$. On Day 0 , the positive $\left[u^{\prime} v^{\prime}\right]$ at approximately $30^{\circ} \mathrm{N}$ weakened, but the $\left[u^{\prime} v^{\prime}\right]$ at $40^{\circ}-65^{\circ} \mathrm{N}$ greatly strengthened. There was adequate transient eddy momentum transported southward north of $65^{\circ} \mathrm{N}$, where a positive $\left[u^{\prime} v^{\prime}\right]$ was located on Day -1 . The convergence of $\left[u^{\prime} v^{\prime}\right]$ reached the maximum near $65^{\circ} \mathrm{N}$, which was beneficial for maintenance of the blocking event. One day later, the positive $\left[u^{\prime} v^{\prime}\right]$ weakened, but the negative $\left[u^{\prime} v^{\prime}\right]$ strengthened. The center of convergence of $\left[u^{\prime} v^{\prime}\right]$ was still located at $65^{\circ} \mathrm{N}$, and on Day +2 , the $\left[u^{\prime} v^{\prime}\right]$ transported southward greatly decreased and moved northward. The zonal wind slightly weakened. On Day +3 , the positive $\left[u^{\prime} v^{\prime}\right]$ weakened and even disappeared. There was no convergence of $\left[u^{\prime} v^{\prime}\right]$ at mid-latitudes, which indicates the collapse of the blocking event.
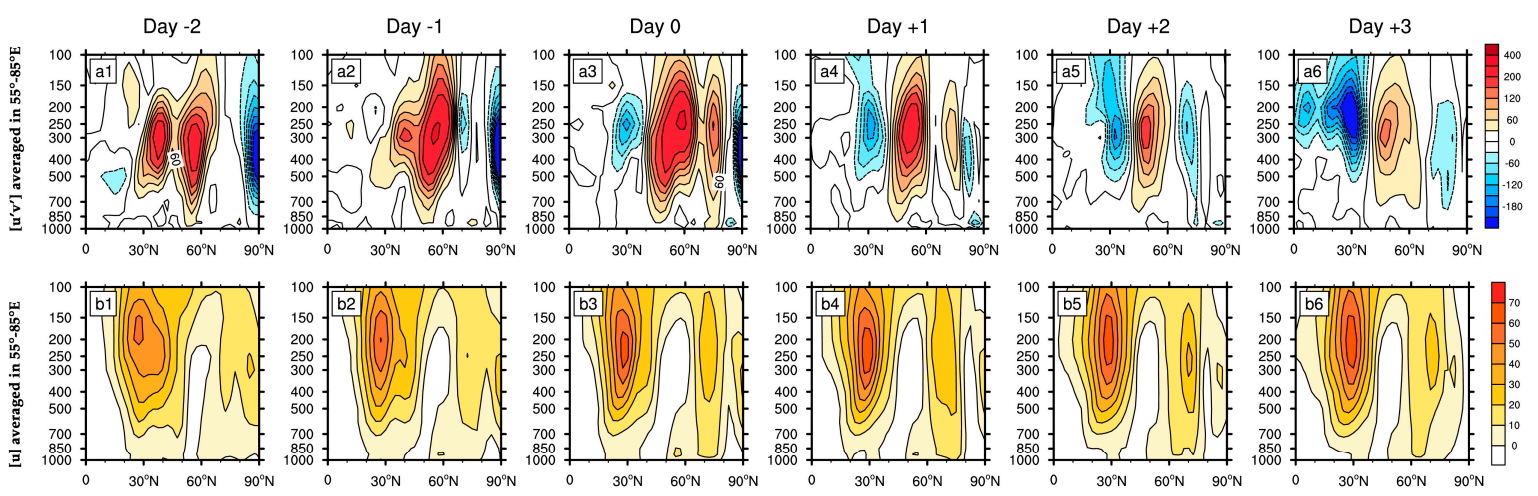

Figure 2. Pressure-latitude cross section in blocking high areas of the mean $\left[u^{\prime} v^{\prime}\right]$ (unit: $\mathrm{m}^{2} \cdot \mathrm{s}^{-2}$ ) and zonal wind $([u])$ (unit: $\left.\mathrm{m} \cdot \mathrm{s}^{-1}\right)$. (a1-a6, b1-b6 indicate the $\left[u^{\prime} v^{\prime}\right]\left(\right.$ unit: $\mathrm{m}^{2} \cdot \mathrm{s}^{-2}$ ) and $[u]\left(\right.$ unit: $\mathrm{m} \cdot \mathrm{s}^{-1}$ ) averaged in $55^{\circ}-85^{\circ} \mathrm{E}$ from January 16 to 21 in 2008 , respectively.)

In addition, the role of momentum transfer by eddy motion was further examined for its important influences on blocking maintenance. For both blocking highs in the 2008 and 2016 events, there are some similarities and differences during momentum transport evolution of transient eddies. As shown above, the convergence center of transient eddy momentum transport was located at $300 \mathrm{hPa}$ in these two events, but the convergence of $\left[u^{\prime} v^{\prime}\right]$ flux was stronger in the 2016 event than in the 2008 event. On Day 0 or Day +1 , there was positive (northward) $\left[u^{\prime} v^{\prime}\right]$ transport south of $40^{\circ} \mathrm{N}$ and negative (southward) [ $\left.u^{\prime} v^{\prime}\right]$ transport north of $65^{\circ} \mathrm{N}$ in the 2016 event. The [ $\left.u^{\prime} v^{\prime}\right]$ at subtropical and high latitude zones was transported into the middle latitude region, which caused momentum aggregation there. The favorable combination of momentum transport at low and high latitudes provided beneficial conditions for blocking events in the 2016 event, which can explain why the intensity of the blocking high was stronger in the 2016 event than in the 2008 event. However, the pattern of transient eddy momentum transport in the 2008 event was just the opposite of what it was in the 2016 event. During 
the blocking high lifetime, the convergence center of $\left[u^{\prime} v^{\prime}\right]$ was further north in the 2016 event, at approximately $65^{\circ} \mathrm{N}$, which may be a reason that the location of the blocking high in the 2016 event is north.
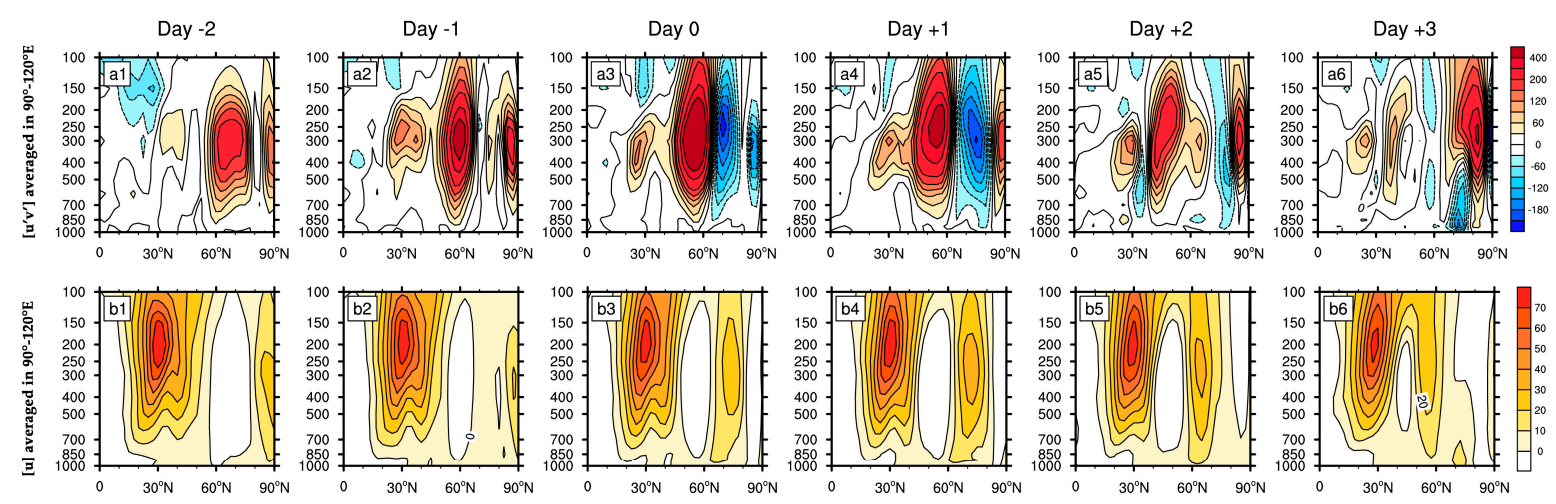

Figure 3. Pressure-latitude cross section in blocking high areas of the mean $\left[u^{\prime} v^{\prime}\right]$ (unit: $\mathrm{m}^{2} \cdot \mathrm{s}^{-2}$ ) and zonal wind $([u])$ (unit: $\left.\mathrm{m} \cdot \mathrm{s}^{-1}\right)$. (a1-a6, b1-b6 indicate the $\left[u^{\prime} v^{\prime}\right]\left(\right.$ unit: $\left.\mathrm{m}^{2} \cdot \mathrm{s}^{-2}\right)$ and $[u]\left(\right.$ unit: $\left.\mathrm{m} \cdot \mathrm{s}^{-1}\right)$ averaged in $90^{\circ}-120^{\circ} \mathrm{E}$ from January 19 to 24 in 2016, respectively.)

\section{Characteristics of Transient Eddy Heat Transport}

Transient eddies are closely related to the change in baroclinic waves in the lower troposphere, which mainly conduct horizontal heat transfer along a favorable gradient, causing the atmosphere to produce a baroclinic pressure response. Due to the blocking process being the result of interaction between barotropic and baroclinic energy [36], we used the heat transport of transient eddies to reflect the thermal mechanism of blocking highs.

Figures 4 and 5 illustrate the vertical distribution of transient eddy heat transport $\left[v^{\prime} T^{\prime}\right]$ and anomalies of temperature [ $\left.T^{\prime}\right]$ structures averaged in the blocking region at longitudes of $55^{\circ}-85^{\circ} \mathrm{E}$ in the 2008 event and $90^{\circ}-120^{\circ} \mathrm{E}$ in the 2016 event, respectively. The transport direction of the symbolic representation of $\left[v^{\prime} T^{\prime}\right]$ is the same as that of $\left[u^{\prime} v^{\prime}\right]$; i.e., positive (negative) $\left[v^{\prime} T^{\prime}\right]$ suggests that the heat of transient eddy is transported northward (southward).

During the 2008 event, on Day -2 there were two centers of northward heat transport: $40 \mathrm{~m} \cdot \mathrm{s}^{-1} \cdot \mathrm{K}$ and $20 \mathrm{~m} \cdot \mathrm{s}^{-1} \cdot \mathrm{K}$ located at $65^{\circ} \mathrm{N}, 200 \mathrm{hPa}$ and $50^{\circ} \mathrm{N}, 500 \mathrm{hPa}$, respectively. The [ $\left.v^{\prime} \mathrm{T}^{\prime}\right]$ transported southward appears at approximately $60^{\circ} \mathrm{N}$ below $300 \mathrm{hPa}$. The vertical distribution feature of the temperature anomaly at north of $35^{\circ} \mathrm{N}$ was in four quadrants, that is, the $\left[T^{\prime}\right]$ at $40^{\circ}-50^{\circ} \mathrm{N}$ over $300 \mathrm{hPa}$ and at $60^{\circ}-80^{\circ} \mathrm{N}$ below $300 \mathrm{hPa}$ were positive, and the $\left[T^{\prime}\right]$ at $40^{\circ}-60^{\circ} \mathrm{N}$ under $300 \mathrm{hPa}$ and north of $80^{\circ} \mathrm{N}$ above $300 \mathrm{hPa}$ were negative. The cold-air pile at approximately $40^{\circ}-60^{\circ} \mathrm{N}$ is related to the $\mathrm{SH}$, which is an important synoptic system for cold events. One day later, the [ $\left.T^{\prime}\right]$ became more obvious, with the transient eddy heat transport at the middle latitude region increasing. The gradient of temperature $\left(-\frac{\partial T}{\partial y}\right)$ decreased. According to the thermal wind principle formula $\left(u_{T}=-R \frac{\partial T}{\partial y}\right)$, where $u_{T}, R$, and $T$ denote the thermal wind, gas constant and temperature, respectively, the thermal wind will weaken, and the zonal wind at mid-latitudes then weakens, which is helpful for blocking development. The convergence of $\left[v^{\prime} T^{\prime}\right]$ transport is presented at approximately $60^{\circ} \mathrm{N}$, which also provides heat for the establishment of a blocking high. On Day 0 , the convergence of $\left[v^{\prime} T^{\prime}\right]$ strengthened and moved southward at approximately $55^{\circ} \mathrm{N}$, and $-\frac{\partial T}{\partial y}$ continued to decrease, which favors blocking high development. One day later, the transport of $\left[v^{\prime} T^{\prime}\right]$ weakened, and the convergence center of $\left[v^{\prime} T^{\prime}\right]$ moved southward to $50^{\circ} \mathrm{N}$. After Day +1 , the transport of $\left[v^{\prime} T^{\prime}\right]$ gradually weakened, as did the convergence of $\left[v^{\prime} T^{\prime}\right]$. The $\left[T^{\prime}\right]$ and $-\frac{\partial T}{\partial y}$ increased, and the blocking high weakened and even collapsed.

During the 2016 event, on Day -2 , the $\left[v^{\prime} T^{\prime}\right]$ at $50^{\circ}-80^{\circ} \mathrm{N}$ over $300 \mathrm{hPa}$ transported northward, and the area below $300 \mathrm{hPa}$ was controlled by negative $\left[v^{\prime} T^{\prime}\right]$. The vertical distribution feature of $\left[T^{\prime}\right]$ with four quadrants was also present north of $30^{\circ} \mathrm{N}$, which is similar to that in the 2008 event. One day later, a small $\left[v^{\prime} T^{\prime}\right]$ transported northward appeared at $50^{\circ}-60^{\circ} \mathrm{N}$, which also connects with the 
positive $\left[v^{\prime} T^{\prime}\right]$ located at over $300 \mathrm{hPa}$ at approximately $50^{\circ}-75^{\circ} \mathrm{N}$. There was also a convergence of $\left[v^{\prime} T^{\prime}\right]$ at $60^{\circ} \mathrm{N}$, which is beneficial for the establishment of blocking events. From Day 0 to Day +1 , the transient eddy heat transport gradually strengthened, which contributed to the convergence of $\left[v^{\prime} T^{\prime}\right]$ increasing and moving southward. The center convergence of $\left[v^{\prime} T^{\prime}\right]$ was located at $55^{\circ} \mathrm{N}$, and the $\left[T^{\prime}\right]$ then becomes bigger, with its center moving southward. After Day +1 , the $\left[v^{\prime} T^{\prime}\right]$ and $\left[T^{\prime}\right]$ rapidly weakened, especially the $\left[v^{\prime} T^{\prime}\right]$ transported southward at $40^{\circ}-70^{\circ} \mathrm{N}$ below $300 \mathrm{hPa}$, which even died off by Day +3 . The $\left[T^{\prime}\right]$ strengthened and gradually moved southward, which resulted in the gradient of temperature increasing. There was no obvious transient eddy heat transport where the blocking high was located, which indicates that there was not enough heat to maintain the establishment and development of the blocking high. In addition, the convergence of transient eddy momentum flux weakened on the term. Combined with other factors, such as diabatic heating, the blocking high collapsed a lot.

During the blocking high process for the two events, there were also many similarities and differences with respect to heat transport, similar to momentum transport. On Day -1 , a great deal of transient eddy heat converged near $60^{\circ} \mathrm{N}$ below $300 \mathrm{hPa}$ in both events, which provided heat for the development of blocking highs. The maximum of $\left[v^{\prime} T^{\prime}\right]$ above $300 \mathrm{hPa}$ at $50-70^{\circ} \mathrm{N}$ in the 2016 event was greater than that in the 2008 event. On Day 0, the convergence of $\left[v^{\prime} T^{\prime}\right]$ strengthened in both events but was stronger in terms of intensity and range in the 2016 event. The position of the center convergence of $\left[v^{\prime} T^{\prime}\right]$ transport in the 2016 event was 5 degrees of latitude north of its position in the 2008 event. This may be due to the position of the blocking high in the 2016 event being more to the north. Different latitudes of convergence affect the intensity of cold air, which brings different weather phenomena. After Day 0 , the convergence of $\left[v^{\prime} T^{\prime}\right]$ weakend and gradually moved southward in the 2008 event, which suggests that the blocking event weakened. However, the [ $\left.v^{\prime} T^{\prime}\right]$ in the 2016 event started to weaken after Day +1 . The gradient of temperature weakened from Day -2 to Day 0 in the 2008 event, but was maintained from Day -2 to Day +1 in the 2016 event. The $-\frac{\partial T}{\partial y}$ weakening led to the reduction of the thermal wind, and the zonal wind then weakened, which was beneficial for the establishment and maintenance of the blocking high. This clarifies the heavier blocking event in the 2016 event. The transport of moisture and the organized release of latent heat by eddies were not considered in this study.
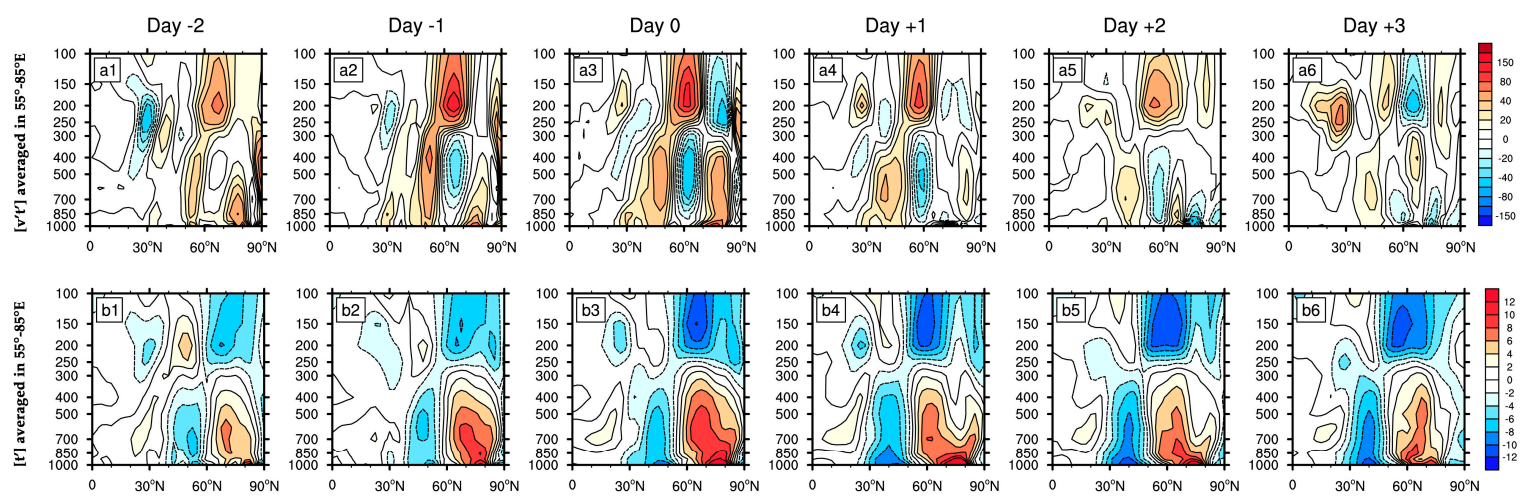

Figure 4. Pressure-latitude cross section in blocking high areas of the mean $\left[v^{\prime} \mathrm{T}^{\prime}\right]\left(\right.$ unit: $\left.\mathrm{m} \cdot \mathrm{s}^{-1} \cdot \mathrm{K}\right)$ and the anomaly temperature $\left[T^{\prime}\right]$ distribution (unit: K). (a1-a6, b1-b6 indicate the $\left[v^{\prime} T^{\prime}\right]$ (unit: $\mathrm{m} \cdot \mathrm{s}^{-1} \cdot \mathrm{K}$ ) and $\left[T^{\prime}\right]$ (unit: $\mathrm{K}$ ) averaged in $55^{\circ}-85^{\circ} \mathrm{E}$ from January 16 to 21 in 2008 , respectively.) 

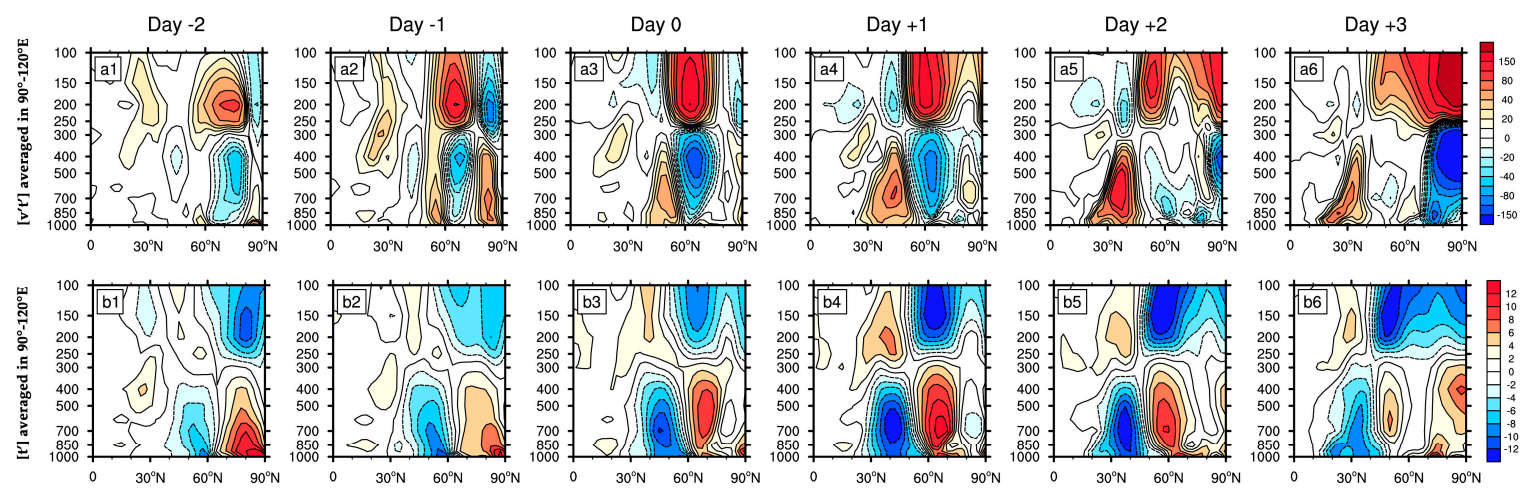

Figure 5. Pressure-latitude cross section in blocking high areas of the mean $\left[v^{\prime} T^{\prime}\right]$ (unit: $\mathrm{m} \cdot \mathrm{s}^{-1} \cdot \mathrm{K}$ ) and the anomaly temperature $\left[T^{\prime}\right]$ distribution (unit: $\left.\mathrm{K}\right) .\left(\mathrm{a} 1-\mathrm{a} 6, \mathrm{~b} 1-\mathrm{b} 6\right.$ indicate the $\left[v^{\prime} \mathrm{T}^{\prime}\right]$ (unit: $\mathrm{m} \cdot \mathrm{s}^{-1} \cdot \mathrm{K}$ ) and $\left[T^{\prime}\right]$ (unit: $\mathrm{K}$ ) averaged in $90^{\circ}-120^{\circ} \mathrm{E}$ from January 19 to 24 in 2016, respectively.)

\section{Related Characteristics of E-P Flux and RWB}

This previous study focused on transport of heat and momentum by transient eddies, indicating the important role of synoptic-scale eddies in the evolution of blocking highs through convergence and divergence of transient eddy flux. As a diagnostic tool, the E-P flux, which takes into account thermal and momentum transport by transient eddies together, can be used to study the stationary wave activities associated with blocking highs. In addition, as the irreversible overturning of potential vorticity in meridional regions on isentropic surfaces [37], RWB is closely related to the physical process of these convergences and divergences of transient eddy flux. Recent studies have shown that transient waves act on the formation and maintenance of blocking highs in the form of cyclonic and anticyclonic RWB [38]. This section tries to evaluate the related characteristics of E-P flux and RWB during the lifetimes of the two blocking highs.

Figure 6 shows the divergence of E-P flux during the blocking highs associated with the two events. The negative (positive) represents convergence (divergence) of E-P flux. E-P flux divergence has an important influence on the evolution of basic zonal wind in the upper-level jet stream region. The acceleration and deceleration of basic zonal flows mainly result from the meridional transportation of perturbation momentum [39]. It is shown that the regions of blocking highs during these two events are characterized by convergence of E-P flux located at the middle level of the troposphere around mid-high latitudes in Figure 6, and the characteristic of convergence is also coincident with that of $\left[v^{\prime} T^{\prime}\right]$ and $\left[u^{\prime} v^{\prime}\right]$ (Figures 2-5). The location center of E-P flux is approximately $60^{\circ} \mathrm{N}, 400 \mathrm{hPa}$, where a blocking high lies. According to the relation $\frac{\partial u}{\partial t} \propto \nabla \cdot F[39]$, the westerly wind will decelerate and even switch to easterly in the region with E-P flux convergence; the $[u]$ in Figures 3 and 4 demonstrates the result that there were easterlies at middle-high latitudes. The convergence of E-P flux supports a beneficial background for the blocking high [39]. Whether in the 2008 event or 2016 event, from Day -2 to Day -1 , the strength of convergence of E-P flux increased, and the zonal easterly accelerated, which would offer helpful circulation conditions for establishment of blocking events. During Day -1 to Day 0, the E-P flux weakened slightly. During the 2008 event, from Day 0 to Day +1 , the convergence of E-P flux increased, yet the increase in E-P flux was maintained until Day +2 in the 2016 event. On some days, such as Day -1 and Day +2 , the latitude of the center of E-P flux convergence was further north in the 2016 event compared with that in the 2008 event. The result is consistent with the conclusion in Sections 3 and 4. By Figures 2-5, whether it is heat or momentum transported by transient eddies, the strength of transport is stronger in the 2016 event. However, such a signal cannot be seen from the E-P flux, which may be related to a limitation of the E-P flux method such that it does not incorporate the role of diabatic heating.

Figure 7 illustrates the variation of Ertel's PV on the $315 \mathrm{~K}$ isentropic surface from Day -2 to Day +3 . It is indicated that there are obvious signals of anticyclonic RWB since 2 days prior to (Day -2 ) the onsets of both blocking events. During the 2008 event starting on Day -2 , air with low PV 
from southwest Europe moved to northeast, and air with high PV from north of the Baikal region invaded to southwest, which formed an overturning of $\mathrm{PV}$ at approximately $40^{\circ}-70^{\circ} \mathrm{N}$ in the Urals region. This overturning became the strongest when the blocking high was established (Day 0 ) and weakened and disappeared gradually, which indicated the end of this anticyclonic RWB. On Day +3 , a new RWB appeared, denoting the occurrence of another blocking event. In the 2016 event, air with low PV from west of Balkash Lake extended to the northeast, and air with high PV from northeast of the Baikal regions stretched to the southwest on Day -2 , forming overturning of PV at approximately $40^{\circ}-80^{\circ} \mathrm{N}$ from northern China to southeastern Russia from Day -1 to Day +1 . Then, such overturning weakened and disappeared, accompanying the end of RWB and collapse of the blocking high. It is shown that although anticyclonic RWB occured, features of RWB were different during these two blocking events. Specifically, RWB in the 2016 event was longer in duration, stronger in intensity, more eastward in longitudes, and more northward in latitudes compared with RWB in the 2008 event. Different features of RWB presented here are consistent with previous results in this study concerning the different characteristics of transient eddy flux during the two blocking highs.

Pelly and Hoskins [27] reported that a blocking event is generally related to RWB. Xie and Bueh [22] further indicated that the blocking activity is primarily induced by an increased frequency and eastward extension of the synoptic anticyclonic RWB. In our study, anticyclonic RWB was observed in both blocking events and is also consistent with the study of Masato et al. [40], which indicates that anticyclonic blocking is the leading type over Europe and Asia. In addition, Weijenborg et al. [41] declared that $70 \%$ of the detected blocking events took place after anticyclonic RWB that occurred on average $6^{\circ}$ south of the climatological storm track position. In our study, we identify the signature of RWB two days prior to the occurrence of blocking highs. Especially for the 2016 event, anticyclonic RWB is clearly seen 2 days before the onset of the blocking high. In addition, Riviere and Orlanski [42] pointed out that the momentum flux transport associated with anticyclonic RWB facilitates the jet stream to move north. In our study, the characteristic of a northward shift in the jet stream is obvious in the 2008 event (Figure 2b1-b3), which indicates wave-mean flow feedback and could partly explain the variation of the jet stream during these two events.
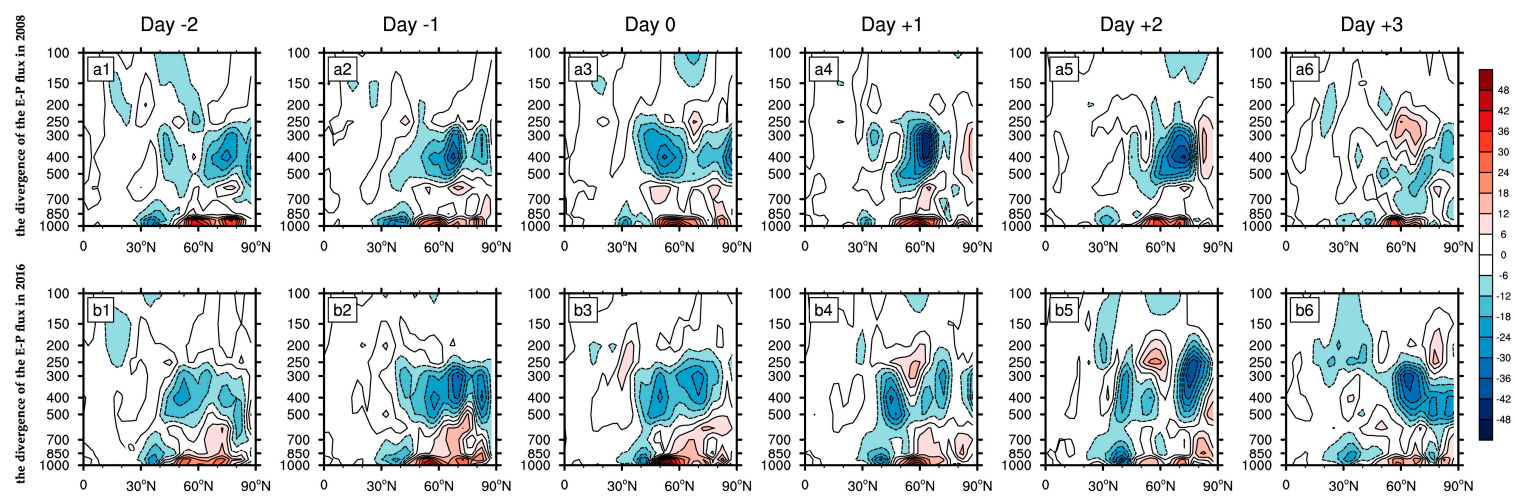

Figure 6. Pressure-latitude cross section of the divergence of Eliassen-Palm (E-P) flux during the two cold events. Unit: $\mathrm{m} \cdot \mathrm{s}^{-2}$. (a1-a6, b1-b6 indicate the divergence of E-P flux from January 16 to 21 in 2008 and January 19 to 24 in 2016, respectively.) 

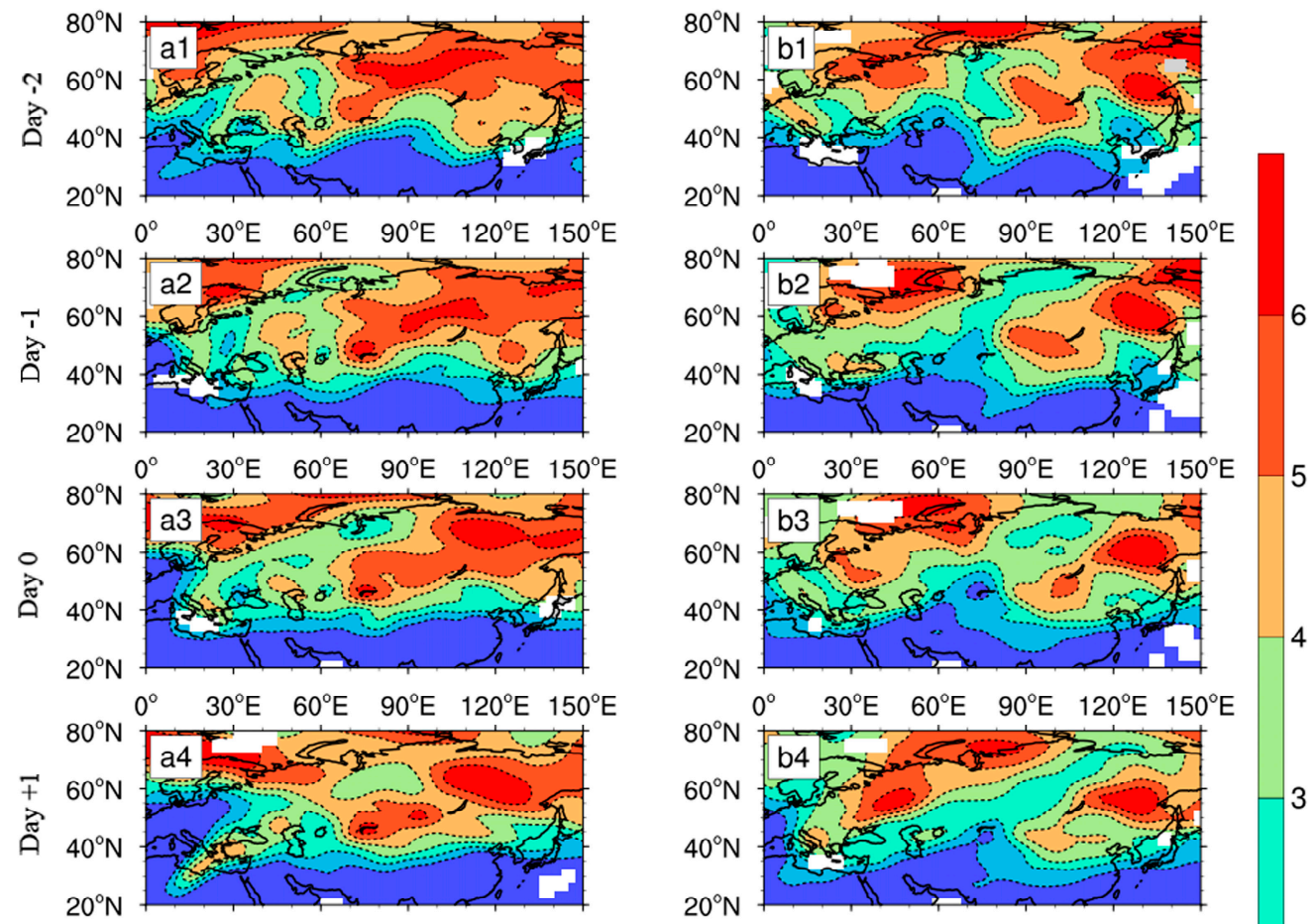

$20^{\circ} \mathrm{N}$
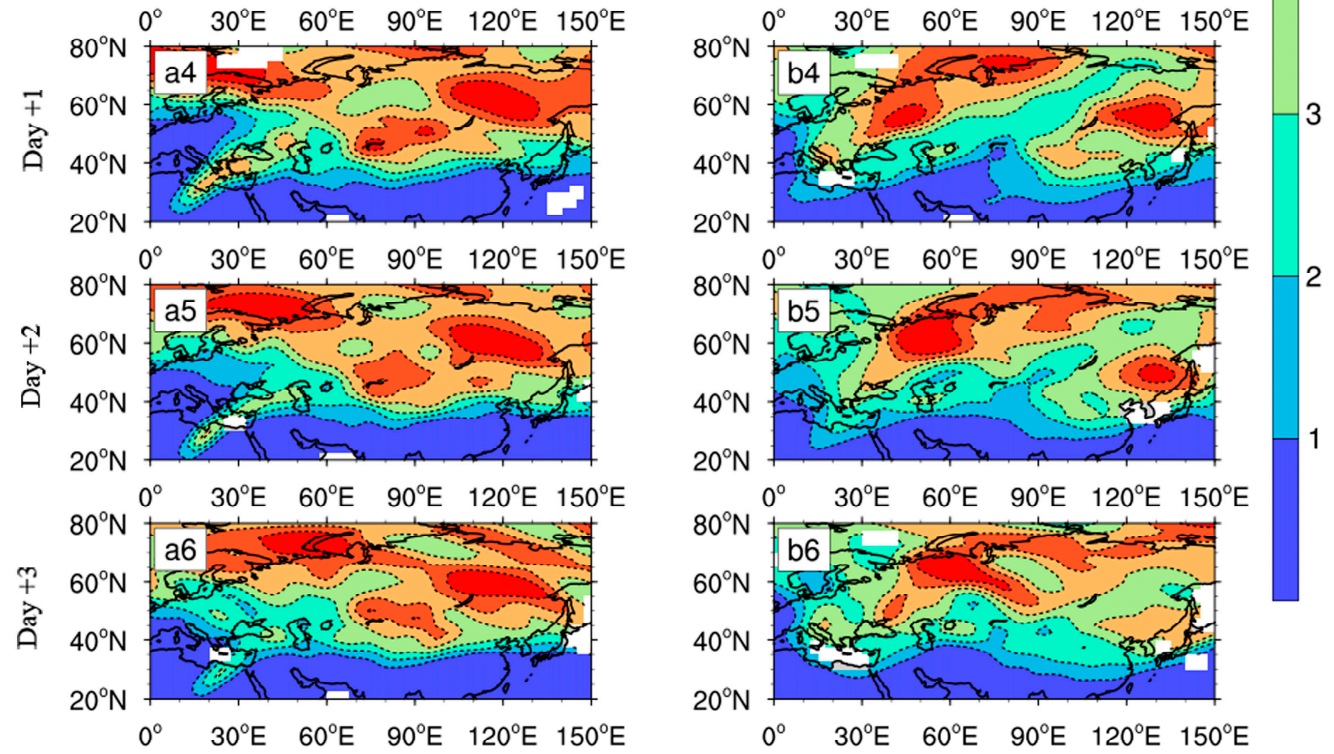

Figure 7. The Ertel's Potential Vorticity (PV) on the $315 \mathrm{~K}$ isentropic surface (unit: PVU, 1 PVU = $\left.10^{-6} \cdot \mathrm{K} \cdot \mathrm{m}^{2} \cdot \mathrm{kg}^{-1} \cdot \mathrm{s}^{-1}\right) \cdot(\mathrm{a} 1-\mathrm{a} 6, \mathrm{~b} 1-\mathrm{b} 6$ indicate PV from January 16 to 21 in 2008 and January 19 to 24 in 2016, respectively. The isoline interval is 1 PVU.)

\section{Conclusions and Discussion}

This work aimed to investigate the characteristics of thermal and momentum transport by transient eddies as well as the features of E-P flux and RWB during blocking highs associated with two cold events in early 2008 and 2016, respectively. These two types of cold events are typical in China. In addition, composite studies based on multiple cases are basically consistent with results in this study (figures not shown). However, it should be noted that all the conclusions in this study were based on two cases rather than climatological analysis. The detailed conclusions are as follows.

Whether in the 2008 or 2016 event, there was a convergence of $\left[u^{\prime} v^{\prime}\right]$ and $\left[v^{\prime} T^{\prime}\right]$ at $55-65^{\circ} \mathrm{N}$, which is a helpful condition for the development of blocking highs. However, there are some differences between them. On Day 0 of the 2008 event, $\left[u^{\prime} v^{\prime}\right]$, which was south or north of $60^{\circ} \mathrm{N}$, was transported northward, and the transport of momentum at north of $60^{\circ} \mathrm{N}$ was less than that at south of $60^{\circ} \mathrm{N}$, showing there was a convergence of $\left[u^{\prime} v^{\prime}\right]$ at $60^{\circ} \mathrm{N}$. On Day 0 of the 2016 event, the $\left[u^{\prime} v^{\prime}\right]$ was transported northward at south of $65^{\circ} \mathrm{N}$ and southward at north of $65^{\circ} \mathrm{N}$. After one day, the location of the [ $\left.u^{\prime} v^{\prime}\right]$ distribution remained unchanged, but the intensity weakened. In consideration of $\left[v^{\prime} T^{\prime}\right]$, it was transported northward at south of $55^{\circ} \mathrm{N}$ and transported southward at north of $55^{\circ} \mathrm{N}$ below $300 \mathrm{hPa}$ 
from Day -1 to Day +3 during the 2008 event. During the 2016 event, transport of $\left[v^{\prime} T^{\prime}\right]$ was stronger, and the convergence was located at $60^{\circ} \mathrm{N}$. Therefore, the convergence of $\left[u^{\prime} v^{\prime}\right]$ and $\left[v^{\prime} T^{\prime}\right]$ was stronger, and the location was more northward in the 2016 event than that in the 2008 event, which is consistent with blocking high characteristics that are stronger in intensity and more northward in location during the 2016 event compared with that during the 2008 event.

Characteristics of the E-P flux and RWB were also investigated to further verify the above results. It is shown that regions with both blocking highs are characterized by the convergence of E-P flux. The westerly wind decelerates in the region of E-P flux convergence [43], which contributes to the onset of blocking highs. In addition, the center of E-P flux convergence was more northward in the 2016 event than in the 2008 event. In view of RWB, the signal of anticyclonic RWB appears on Day -2 in the two events. However, the overturning of $\mathrm{PV}$ appears at $40^{\circ}-70^{\circ} \mathrm{N}, 50^{\circ}-80^{\circ} \mathrm{E}$ with weaker intensity in the 2008 event but presents at $40^{\circ}-80^{\circ} \mathrm{N}, 60^{\circ}-120^{\circ} \mathrm{E}$ with stronger intensity in the 2016 event. Basically, in the 2016 event, the anticyclonic RWB occurred with longer duration, stronger intensity, and more north-eastward location compared with that in the 2008 event.

All the above results can largely explain different characteristics of blocking highs during the two cold events from the perspective of transient eddies. Consequently, different weather phenomena in the 2008 and 2016 events were observed. Due to the stronger and more northerly blocking high in the 2016 event, a great deal of cold air associated with the polar vortex poured along the front of the high-pressure ridge in a short time with a great release, which resulted in a large-scale sharp drop in temperature and a strong northerly gale, called a cold wave, in most regions of China [24]. However, the blocking high was weaker and moderate with longer duration in the 2008 event than that in the 2016 event, which made cold air diffuse southward by small streams instead of a large cold air attack, and thus, brought long-duration low temperatures to southern regions of China. Moreover, the warm vapor associated with the Western Pacific Subtropical High (WPSH) was also anomalously strong in early 2008, producing an extreme low-temperature, snowfall, and freezing disaster event accompanied by the long-duration cold air guided by blocking highs during early 2008. In addition to blocking highs, there are other factors that influence the formation of low-temperature events in Eastern Asia, including the polar vortex [44], the El Nino-Southern Oscillation [45], and the NAO [46]. This study focused on the momentum and heat transport of transient eddies in blocking highs during two cold events. Additionally, although theory about RWB is complicated, the discussion of RWB in Section 5 only considered the topic of this study. In further studies, the relationship between blocking highs and upper-level jet can be investigated by the theory of RWB. In addition, because blocking highs are a result of interactions between different large-scale waves [28], stationary momentum and heat fluxes should also be considered.

Author Contributions: Conceptualization, Y.L. (Yan Li); Data curation, J.Z. (Jinyu Zhang) and J.Z. (Jianlei Zhu); Formal analysis, Y.L. (Yao Lu); Funding acquisition, Y.L. (Yan Li); Project administration, Y.L. (Yao Lu); Validation, Y.L. (Yan Li ) and J.F.; Writing - original draft, Y.L. (Yan Li); Writing - review \& editing, Y.L. (Yao Lu), J.Z. and J.F.

Funding: This research was funded by the Natural Science Foundation of China (41775051; 41705131), and Gansu Natural Science Foundation (18JR3RA301).

Conflicts of Interest: The authors declare no conflict of interest.

\section{References}

1. Chen, T.C.; Yen, M.C.; Huang, W.R.; Gallus, W.A. An East Asian cold surge: Case study. Mon. Wea. Rev. 2002, 130, 2271-2290. [CrossRef]

2. Cui, L.; Shi, J.; Du, H.; Wen, K. Characteristics and trends of climatic extremes in China during 1959-2014. J. Trop. Meteorol. 2017, 22, 368-379.

3. Seneviratne, S.I.; Nicholls, N.; Easterling, D.; Goodess, C.M.; Kanae, S.; Kossin, J.; Luo, Y.; Marengo, J.; Mcinnes, K.; Rahimi, M. Changes in climate extremes and their impacts on the natural physical environment: An overview of the IPCC SREX report. In Proceedings of the Egu General Assembly Conference, Vienna, Austria, 22-27 April 2012; p. 12566. 
4. Tao, S.Y.; Wei, J. Severe snow and freezing rain in January 2008 in Southern China. Clim. Environ. Res. 2008, 13, 337-350.

5. Yao, Y.; Luo, D.; Dai, A.; Simmonds, I. Increased quasi stationarity and persistence of winter Ural blocking and Eurasian extreme cold events in response to Arctic warming. Part I: Insights from observational analyses. J. Clim. 2017, 30, 3549-3568. [CrossRef]

6. Rex, D.F. Blocking action in the middle troposphere and its effects upon regional climate. I: An aerological study of blocking action. Tellus 1950, 2, 196-211. [CrossRef]

7. Takaya, K.; Nakamura, H. Mechanisms of intraseasonal amplification of the cold Siberian high. J. Atmos. Sci. 2005, 62, 4423-4440. [CrossRef]

8. Lau, N.C.; Lau, K.M. The structure and energetics of mid-latitude disturbances accompanying cold-air outbreaks over East Asia. Mon. Wea. Rev. 1984, 112, 1309-1327. [CrossRef]

9. Yeh, T.C. On energy dispersion in the atmosphere. J. Atmos. Sci. 2010, 6, 1-16. [CrossRef]

10. Rossby, C.G. On the dynamics of certain types of blocking waves. Chin. J. Geophys-Ch. 1951, 2, 1-13.

11. Charney, J.G.; DeVore, J.G. Multiple flow equilibria in the atmosphere and blocking. J. Atmos. Sci. 1979, 36, 1205-1216. [CrossRef]

12. Luo, D. Interaction between envelope soliton vortex pair blocks and synoptic-scale eddies in an inhomogeneous baroclinicity environment. Q. J. Roy. Meteor. Soc. 2010, 131, 125-154. [CrossRef]

13. Li, S. Impact of Northwest Atlantic SST anomalies on the circulation over the Ural Mountains during early winter. J. Meteorol. Soc. Jpn. 2004, 82, 971-988. [CrossRef]

14. Luo, D.; Xiao, Y.; Diao, Y.; Dai, A.; Franzke, C.L.E.; Simmonds, I. Impact of Ural blocking on winter warm arctic-cold Eurasian Anomalies. Part II: The link to the North Atlantic Oscillation. J. Clim. 2016, 29, 3949-3971. [CrossRef]

15. Nath, D.; Chen, W. Impact of planetary wave reflection on tropospheric blocking over the Urals-Siberia region in January 2008. Adv. Atmos. Sci. 2016, 33, 309-318. [CrossRef]

16. Zhu, W.J.; Sun, Z.B. Effects of eddy ageostrophic geopotentiaI fluxes on the maintenance of storm tracks. Chinese. J. Atmos. Sci. 2001, 25, 71-78.

17. Nakamura, H.; Wallace, J.M. Observed changes in baroclinic wave activity during the life cycles of low-frequency circulation anomalies. J. Atmos. Sci. 1990, 47, 1100-1116. [CrossRef]

18. Chen, W.Y. Effects of transient eddies on blocking flows: General circulation model experiments. Mon. Wea. Rev. 2009, 120, 787-801. [CrossRef]

19. Athar, H.; Lupo, A.R. Scale analysis of blocking events from 2002 to 2004: A case study of an unusually persistent blocking event leading to a heat wave in the gulf of Alaska during August 2004. Adv. Meteorol. 2010, 12, 185-194. [CrossRef]

20. Xu, H.; Jin, R.H. Analysis on the effect of the transient eddy on Ural blocking high in 2008. Plateau. Meteor. 2011, 45, 286-298.

21. Yun, K.S.; Seo, Y.W.; Ha, K.J.; Lee, J.Y.; Kitoh, A. The seasonally varying effect of the Tibetan Plateau on Northern Hemispheric blocking frequency and amplitude. Clim. Dynam. 2016, 47, 2527-2541. [CrossRef]

22. Xie, Z.W.; Bueh, C. Blocking features for two types of cold events in East Asia. J. Meteor. Res. 2017, 31, 309-320. [CrossRef]

23. Bueh, C.; Ning, S.; Xie, Z. Large-scale circulation anomalies associated with persistent low temperature over Southern China in January 2008. Atmos. Sci. Lett. 2011, 12, 273-280. [CrossRef]

24. Qian, C.; Wang, J.; Dong, S.; Burke, C.; Ciavarella, A.; Dong, B.; Freychet, N.; Lott, F.C.; Tett, S.F.B. Human influence on the record-breaking cold event in January of 2016 in Eastern China. B. Am. Meteorol. Soc. 2017, 99, S118-S122. [CrossRef]

25. Kalnay, E.; Kanamitsu, M.; Kistler, R.; Collins, W.; Deaven, D.; Gandin, L.; Iredell, M.; Saha, S.; White, G.; Woollen, J.; Zhu, Y.; Leetmaa, A.; Reynolds, R.; Joseph, J.D. The NCEP/NCAR 40-year reanalysis project. B. Am. Meteorol. Soc. 1996, 77, 437-472. [CrossRef]

26. Tibaldi, S.; Molteni, F. On the operational predictability of blocking. Tellus. A 1990, 42, 23. [CrossRef]

27. Pelly, J.L.; Hoskins, B.J. A new perspective on blocking. J. Atmos. Sci. 2003, 60, 743-755. [CrossRef]

28. Austin, J.F. The blocking of middle latitude westerly winds by planetary waves. Quart. J. R. Meteor. Soc. 1980, 106, 327-350. [CrossRef]

29. Holton, J. Introduction to Dynamic Meteorology, 4th ed.; Academic Press: Cambridge, MA, USA, 1979. [CrossRef] 
30. Andrews, D.G.; Mcintyre, M.F. Planetary waves in horizontal and vertical shear: asymptotic theory for equatorial waves in weak shear. J. Atmos. Sci. 1976, 33, 2049-2053. [CrossRef]

31. Teubler, F.; Riemer, M. Dynamics of Rossby wave packets in a quantitative potential vorticity potential temperature framework. J. Atmos. Sci. 2016, 73, 1063-1081. [CrossRef]

32. Hitchman, M.H.; Huesmann, A.S. A seasonal climatology of Rossby wave breaking in the 320-2000-K layer. J. Atmos. Sci. 2007, 64, 1922-1940. [CrossRef]

33. Nie, Y.; Sun, L.; Wang, D.M.; Li, D. Possible causes for the sudden drop of air temperature in the Northern Hemisphere from early-to mid-winter. Meteor. Mon. 2016, 42, 1223-1229.

34. Wang, D.H.; Liu, C.J.; Liu, Y.; Wei, F.Y.; Zhao, N.; Jiang, Z.N.; Li, Y.; Chen, G.Y.; Wang, Y.F.; Shi, X.H.; et al. A preliminary analysis of features and causes of the snow storm event over the Southern China in January2008. Acta Meteorol. Sin. 2009, 23, 374-386.

35. Ren, X.J.; Yang, X.Q.; Zhou, T.J.; Fang, J.B. Diagnostic comparison of wintertime East Asian subtropical jet and polar-front jet: Large-scale characteristics and transient eddy activities. Acta Meteorol. Sin. 2011, 25, 21-33. [CrossRef]

36. Trenberth, K.E. An assessment of the impact of transient eddies on the zonal flow during a blocking episode using localized eliassen-palm flux diagnostics. J. Atmos. Sci. 1986, 43, 2070-2087. [CrossRef]

37. Thorncroft, C.D.; Hoskins, B.J.; Mcintyre, M.E. Two paradigms of baroclinic-wave life-cycle behaviour. Quart. J. R. Meteor. Soc. 1993, 119, 17-55. [CrossRef]

38. Woollings, T.; Hoskins, B.; Blackburn, M.; Berrisford, P. A new Rossby wave-breaking interpretation of the North Atlantic Oscillation. J. Atmos. Sci. 2008, 65, 609-626. [CrossRef]

39. Zhang, P.; Ni, Y.Q. The effect of topographic forcing on the formation and maintenance of blocking. Adv. Atmos. Sci. 1991, 8, 317-326.

40. Masato, G.; Hoskins, B.J.; Woollings, T.J. Wave-breaking characteristics of mid-latitude blocking. Q. J. R. Meteorol. Soc. 2012, 138, 1285-1296. [CrossRef]

41. Weijenborg, C.; Vries, H.D.; Haarsma, R.J. On the direction of Rossby wave breaking in blocking. Clim. Dyn. 2012, 39, 2823-2831. [CrossRef]

42. Rivière, G.; Orlanski, I. Characteristics of the Atlantic storm-track eddy activity and its relation with the North Atlantic oscillation. J. Atmos. Sci. 2007, 64, 241-266. [CrossRef]

43. Zhang, H.D.; Lu, W.S.; Li, T. Study on the northern hemisphere e-p flux and its relation with subtropical high. J. Nanjing. Mrteor. 2002, 25, 587-594.

44. Kretschmer, M.; Coumou, D.; Agel, L.; Barlow, M.; Tziperman, E.; Cohen, J. More-persistent weak stratospheric polar vortex states linked to cold extremes. B. Am. Meteorol. Soc. 2018, 99, 49-60. [CrossRef]

45. Rusticucci, M.; Vargas, W. Cold and warm events over argentina and their relationship with the ENSO phases: risk evaluation analysis. Int. J. Climatol. 2002, 22, 467-483. [CrossRef]

46. Cattiaux, J.; Vautard, R.; Cassou, C.; Yiou, P.; Masson-Delmotte, V.; Codron, F. Winter 2010 in europe: A cold extreme in a warming climate. Geophys. Res. Lett. 2015, 37, 114-122. [CrossRef]

(C) 2019 by the authors. Licensee MDPI, Basel, Switzerland. This article is an open access article distributed under the terms and conditions of the Creative Commons Attribution (CC BY) license (http://creativecommons.org/licenses/by/4.0/). 